\title{
Frazil-ice entrainment of sediment: large-tank laboratory experiments
}

\author{
Lars Henrik Smedsrud \\ Geophysical Institute, University of Bergen, Allégaten 70, N-5007 Bergen, Norway
}

\begin{abstract}
Laboratory experiments that simulate natural ice-formation processes and sediment entrainment in shallow water are presented. A $10-30 \mathrm{~cm} \mathrm{~s}^{-1}$ current was forced with impellers in a $20 \mathrm{~m}$ long, $1 \mathrm{~m}$ deep indoor tank. Turbulence in the flow maintained a suspension of sediments at concentrations of $10-20 \mathrm{mg} \mathrm{L}^{-1}$ at $0.5 \mathrm{~m}$ depth. Low air temperatures $\left(\sim-15^{\circ} \mathrm{C}\right)$ and $5 \mathrm{~m} \mathrm{~s}^{-1}$ winds resulted in total upward heat fluxes in the range $140-260 \mathrm{~W} \mathrm{~m}^{-2}$. The cooling produced frazil-ice crystals up to $2 \mathrm{~cm}$ in diameter with concentrations up to $4.5 \mathrm{~g} \mathrm{~L}^{-1}$ at $0.5 \mathrm{~m}$ depth. Considerable temporal variability with time-scales of $<1 \mathrm{~min}$ was documented. A close to constant portion of the smaller frazil crystals remained in suspension. After some hours the larger crystals, which made up most of the ice volume, accumulated as slush at the surface. Current measurements were used to calculate the turbulent dissipation rate, and estimates of vertical diffusion were derived. After 5-8 hours, sediment concentrations in the surface slush were normally close to those of the water. After 24 hours, however, they were 2-4 times higher. Data indicate that sediment entrainment depends on high heat fluxes and correspondingly high frazilice production rates, as well as sufficiently strong turbulence. Waves do not seem to increase sediment entrainment significantly.
\end{abstract}

\section{INTRODUCTION}

Sediment can be found inside or on top of sea ice in all parts of the ice-covered Arctic Ocean (Barnes and others, 1982; Nürnberg and others, 1994; Landa and others, 1998). Levels of sediment in the ice are often patchy in nature, usually in the range 5-500 $\mathrm{mg} \mathrm{L}^{-1}$, but vary both horizontally and vertically down to the centimetre scale. The entrainment processes appear to be governed by episodic events (Eicken and others, 2000).

Although in situ field observations of sediment entrainment are very rare, many researchers assume that much of the entrainment is due to formation of frazil ice in shallow water with sediment in suspension (Nürnberg and others, 1994). This process is termed suspension freezing (Reimnitz and others, 1992) and probably takes place over shallow shelf areas during ice formation in autumn, or in flaw leads and polynyas during winter. High entrainment rates of the process have been documented in experiments in small tanks with a short duration ( $<1$ hour), but the turbulence and heat flux have not been quantified (Kempema and others, 1993; Reimnitz and others, 1993; Ackermann and others, 1994).

This paper presents results of four laboratory experiments

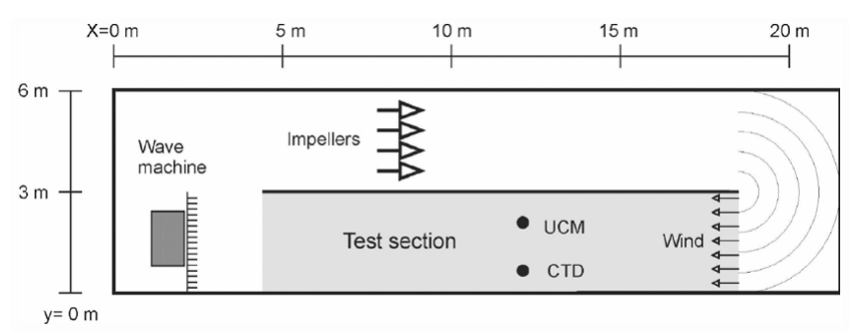

Fig. 1. A sketch of the experimental tank at HSVA as seen from above. Positions of the instruments during experiments are indicated. performed in a $20 \mathrm{~m}$ long, $1 \mathrm{~m}$ deep tank. Measurements of currents, frazil-ice concentration and crystal size, and sediment concentration and particle size are given and discussed with reference to earlier laboratory experiments and natural conditions. The aim of the discussion is to understand how efficiently frazil crystals can entrain sediment into the surface ice layer.

\section{SET-UP}

Experiments were performed in the Arctic Environmental Test Basin, a cold room with a $1 \mathrm{~m}$ deep tank at the Hamburg Ship Model Basin (HSVA), Germany. Data from two different experimental periods are presented here: Interice I (November 1996-February 1997; Eicken and others, 1999) and Interice II (December 1998; Haas and others, 1999). The first basic results on sediment entrainment into ice from Interice I were presented by Smedsrud (1998) and Lindemann and Smedrud (1999). The present paper is based on 3 weeks of experiments, mostly from Interice II.

The flow in the tank was $3 \mathrm{~m}$ wide (Fig. 1) and driven by four impellers. The tank was equipped with a wave machine capable of generating waves with a $10 \mathrm{~cm}$ amplitude, and with wind propellers producing winds of up to $5 \mathrm{~m} \mathrm{~s}^{-1}$ over the water surface. The air temperature in the cold room can be regulated through a cooling system with a capacity of $69.7 \mathrm{~kW}$, having cooling ribs in the ceiling. During experiments the air temperature was maintained below $-10^{\circ} \mathrm{C}$, and most of the time temperatures were between $-14^{\circ}$ and $-18^{\circ} \mathrm{C}$.

In the beginning of each experiment, the test section was cleared of slush and ice. At the impeller side of the tank a $\sim 20 \mathrm{~cm}$ thick, solid layer of ice persisted through the experiments. 


\begin{tabular}{|c|c|c|c|c|}
\hline & \multicolumn{4}{|c|}{ Experiment } \\
\hline & $A$ & $B$ & $C$ & $D$ \\
\hline Air temperature $T_{\mathrm{a}}\left({ }^{\circ} \mathrm{C}\right)$ & -10.43 & -17.17 & -13.85 & -14.11 \\
\hline Current speed $\left(\mathrm{cm} \mathrm{s}^{-1}\right)$ & 32.03 & 25.05 & 32.12 & 9.12 \\
\hline Wave height $(\mathrm{cm})$ & 0 & 0 & 10 & 10 \\
\hline Duration $(\mathrm{h})$ & 25 & 24 & 24 & 6 \\
\hline rms fluctuation $q\left(\mathrm{~cm} \mathrm{~s}^{-1}\right)$ & 9.3 & 7.4 & 10.3 & 6.8 \\
\hline Turbulent dissipation rate $\epsilon\left(\mathrm{W} \mathrm{kg}^{-1}\right)$ & $4.3 \times 10^{-4}$ & $3.5 \times 10^{-4}$ & $3.7 \times 10^{-4}$ & $3.7 \times 10^{-6}$ \\
\hline Turbulent diffusion $K\left(\mathrm{~m}^{2} \mathrm{~s}^{-1}\right)$ & $3.4 \times 10^{-3}$ & $1.7 \times 10^{-3}$ & $5.9 \times 10^{-3}$ & $111.4 \times 10^{-3}$ \\
\hline Heat flux $Q_{\mathrm{f}}\left(\mathrm{W} \mathrm{m}^{-2}\right)$ & 160.2 & 257.2 & 190.4 & 135.4 \\
\hline Water cooling rate $\Delta T_{\mathrm{w}} / \Delta t\left({ }^{\circ} \mathrm{Ch}^{-1}\right)$ & $-1.9 \times 10^{-3}$ & $-1.7 \times 10^{-3}$ & $-3.6 \times 10^{-3}$ & $-5.0 \times 10^{-3}$ \\
\hline Salinity increase rate $\Delta S_{\mathrm{w}} / \Delta t\left(\mathrm{psuh}^{-1}\right)$ & $29.2 \times 10^{-3}$ & $43.8 \times 10^{-3}$ & $34.7 \times 10^{-3}$ & $22.0 \times 10^{-3}$ \\
\hline Frazil-ice concentration $C_{\mathrm{i}}\left(\mathrm{g} \mathrm{L}^{-1}\right)$ & 1.1 & 0.8 & 0.9 & 3.0 \\
\hline Frazil-ice production rate $\Delta C_{\mathrm{i}} / \Delta t\left(\mathrm{~g} \mathrm{~L}^{-1} \mathrm{~h}^{-1}\right)$ & 0.75 & 1.17 & 0.88 & 0.63 \\
\hline Sediment type & Silt and sand & Silt and sand & Silt and sand & Clay and silt \\
\hline Initial sediment conc. SPM $\left(\mathrm{mg} \mathrm{L}^{-1}\right)$ & 12.3 & 18.1 & 16.3 & 12.0 \\
\hline Max. sediment conc. in ice IRS $\left(\mathrm{mg} \mathrm{L}^{-1}\right)$ & 44.3 & 198.5 & 21.8 & 21.2 \\
\hline
\end{tabular}

Note: Values are averages over the duration of experiments unless otherwise stated.

The water had a salinity of 36-38 psu (practical salinity units; \%o) initially, and was always close to the freezing point because of the permanent ice cover. Levels of supercooling were typically $0.01^{\circ} \mathrm{C}$, and persisted through the entire experiment. Sediment was added to the tank, resulting in mass concentrations in the range $10-20 \mathrm{mg} \mathrm{L}^{-1}$. Key parameters of each experiment are given in Table 1 for later reference. Key features of experiment D are presented in Smedsrud (1998), and a more detailed description of all experiments is given in Smedsrud (2000).

\section{METHODS}

Currents were measured with either an ADV (acoustic Doppler velocity meter; Nortek, Norway) sampling at $25 \mathrm{~Hz}$, or a UCM (ultrasonic current meter; NE Sensortek, Norway) sampling at $2 \mathrm{~Hz}$. Both instruments measure three components of current velocity with an accuracy of \pm 5 $\mathrm{mm} \mathrm{s}^{-1}$. Currents in the "test section" were sampled $5 \mathrm{~min}$ every hour during experiments, and, unless otherwise mentioned, at $0.35 \mathrm{~m}$ depth in the positions shown in Figure 1.

A mini CTD (conductivity-, temperature- and depthmeasuring device; Meerestechnik Elektronik, Germany) was used to measure water temperature and salinity once every minute. The temperature sensor was calibrated 2 weeks before the experiments to an accuracy of $\pm 0.001^{\circ} \mathrm{C}$, while the conductivity sensor was accurate to $\pm 0.01 \mathrm{psu}$. Water samples were taken twice every day to check the calibration of the conductivity measurements with a Portasal 8410-A salinometer with an accuracy of $\pm 0.003 \mathrm{psu}$ at the University of Bergen, Norway. Air temperatures were sampled every 10 min with a Tiny-talk temperature sensor, with a $0.1^{\circ} \mathrm{C}$ resolution and accuracy.

Video images of frazil crystals were recorded using a Canon Hi8 camera and a macrolens filmed through polarized glass. The crystals were scooped out of the water using a $9 \mathrm{~cm}$ diameter glass plate. Still images were processed from the video, and the numbers of crystals in different size groups were counted directly on the monitor to determine crystal-size distributions. Frazil crystals down to $100 \mu \mathrm{m}$ were resolved, and a total of 435 crystals were counted at three different stages of experiment D. Samples of the congealed surface slush (solid ice) were taken to make thin sections and to document the crystal structure.

Suspended frazil concentration was determined by holding a $5 \mathrm{~L}$ water bottle, open at both ends, in the water column at various depths. Slush (frazil ice and water) was collected by draining the bottle contents through a commercial sieve (mesh width $0.5 \mathrm{~mm}$ ). The slush was allowed to melt in clean boxes, and the salinity of the melt was determined using a laboratory conductometer WTW LF 191 (Wissenschaftlich Technische Werkstatten, accuracy \pm 0.1 psu). The slush volume was determined using a graduated cylinder (accuracy $\pm 1 \mathrm{~mL}$ ). The true frazil-ice concentration was then calculated, assuming zero salinity for the ice, and bulk salinity of the tank for the water.

The second method of measuring suspended frazil concentration was with an a-3 absorption meter(Wetlabs, Oregon, U.S.A.) modified to measure light absorption at 900 and $975 \mathrm{~nm}$ wavelengths at $5.8 \mathrm{~Hz}$. The meter was used vertically, with water flowing between the source and detector units, and all values are therefore vertical averages over these $10 \mathrm{~cm}$. It was calibrated in a laboratory test with freshwater frazil ice, and has a noise level that translates into an error of $0.1 \mathrm{~g} \mathrm{~L}^{-1}$ (Pegau and others, 1996). At $975 \mathrm{~nm}$ there is a peak in the absorption spectrum of water, which makes it possible to calculate the changes in absorption due to the change in frazil-ice concentrations. A pure water sampling done during the experiment serves as a reference frazil concentration of zero.

Sediment concentrations were determined either by filtering sample water directly through pre-weighed $0.45 \mu \mathrm{m}$ membrane filters, or by melting ice samples and filtering the resulting meltwater. Mass concentrations were calculated by subtracting the initial filter weight from the sedimentcontaining filters. Due to the low sediment content the weighing was performed on a sensitive micro-balance.

Size distribution of the sediment suspended in water was determined from the bulk sample added to the tank using a standard sieving and sedigraph technique. First the original sediment sample was dried to get the initial dry weight, and further wet-sieved to distinguish the sand fraction $(>63 \mu \mathrm{m})$. The coarse fraction was dry-sieved to get the weight of the different coarse grain-size fractions $(63-125 \mu \mathrm{m}, 125-250 \mu \mathrm{m}$, 


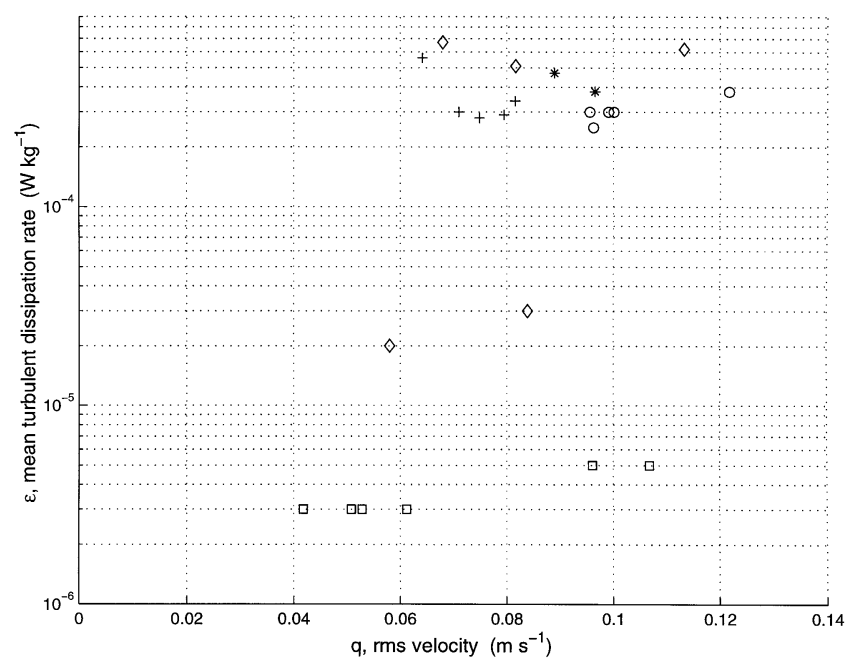

Fig. 2.Values for the rms velocity $q$ and the turbulent dissipation rate $\epsilon$, during the experiments. Experiments $A(*)$ and $B(+)$ are forced with a $30 \mathrm{~cm} \mathrm{~s}^{-1}$ current, $C(\mathrm{O})$ with $30 \mathrm{~cm} \mathrm{~s}^{-1}$ current and $10 \mathrm{~cm}$ waves, and $D(\square)$ with a $10 \mathrm{~cm} \mathrm{~s}^{-1}$ current and $10 \mathrm{~cm}$ waves. Values showing the horizontal variation with the same forcing as experiment $C$ are shown as $\diamond$.

250-500 $\mu \mathrm{m}, 500 \mu \mathrm{m}-1 \mathrm{~mm}$ and $>1 \mathrm{~mm}$ ). The grain-size of the silt and clay fraction $(<63 \mu \mathrm{m})$ was determined by their settling velocities. The accuracy for a standard sample is $\pm 0.02 \mathrm{mg} \mathrm{L}^{-1}$.

Size distribution of the sediment in the ice was determined using a scanning electron microscope (SEM). The samples were filtered on $0.22 \mu \mathrm{m}$ Millipore filters, and gold-palladium was damped on. The different grain-sizes were divided into groups, and the number of grains in each group was then estimated by counting along the filter using magnifications of 100-4000.

\section{RESULTS}

\subsection{Gurrents and turbulence}

Horizontal mean velocities during the four experiments were in the range $9.1-32.1 \mathrm{~cm} \mathrm{~s}^{-1}$, as given in Table 1. Before the experiments started, the UCM was used to determine variations within the test section, both across the flow and with depth. For the mean speed, horizontal variations across the flow were typically $\pm 3 \mathrm{~cm} \mathrm{~s}^{-1}$, and in the vertical $\pm 1 \mathrm{~cm} \mathrm{~s}^{-1}$.

The flow was clearly turbulent, and eddies were easily observed at the surface. Turbulence caused four important features in the experiments: (i) downward diffusion of frazil, (ii) upward diffusion of sediment, (iii) collision and aggregation between frazil and sediment, and (iv) diffusion of heat and salinity.

The turbulent strength may be indicated by $q^{2}=$ $\overline{\left(u^{\prime}\right)^{2}+\left(v^{\prime}\right)^{2}+\left(w^{\prime}\right)^{2}}$, the rms value of the velocity fluctuations. $u$ is the speed in the direction along the tank and with the flow, $v$ is the speed across the tank, and $w$ is the vertical speed. The fluctuating part is $u^{\prime}=u-\bar{u}$. The value of $q$ had an overall range of $4-12 \mathrm{~cm} \mathrm{~s}^{-1}$ for all experiments (Fig. 2). In experiment D the UCM was logging at different depths, and $q$ varied significantly with depth, from $10.7 \mathrm{~cm} \mathrm{~s}^{-1}$ at 0.15 $\mathrm{m}$ depth to $4.2 \mathrm{~cm} \mathrm{~s}^{-1}$ at $0.5 \mathrm{~m}$ depth (Fig. 2; depths are not shown). In addition, the increasing surface slush layer seemed to dampen $q$ in the near-surface layer $(0.15 \mathrm{~m})$ quite efficiently, from 10.7 to $5.3 \mathrm{~cm} \mathrm{~s}^{-1}$ during 3 hours.

Calculated values of $q$ from the four experiments are

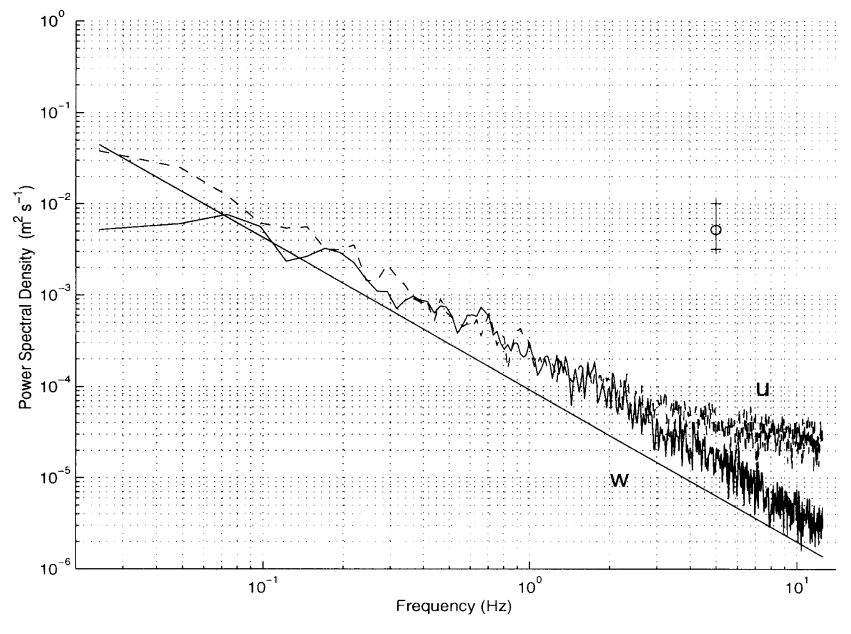

Fig. 3. PSD from $0.35 \mathrm{~m}$ depth at the beginning of experiment $A, u$ (dashed line) and w (solid line) components. The error bar represents the $95 \%$ confidence interval. The straight line is the theoretical $f^{-5 / 3}$ spectrum, using the measured and the calculated $\bar{\epsilon}$.

shown in Figure 2 together with the turbulent dissipation rate $\epsilon$. Mean values for each experiment are shown in Table 1. $\epsilon$ expresses how much energy is being transferred into heat at the molecular level by friction. In a stationary process, such as the experimental tank with constant energy input from the impellers, $\epsilon$ also indicates how much energy is being transferred down through the different turbulent scales, from the largest eddies of the flow down to the smallest ones (Tennekes and Lumley, 1994).

As the main focus is vertical diffusion, and the geometry of the acoustic sensors on the current meter allows minimum instrument noise on the vertical component $w$, dissipation is calculated using the power spectral density (PSD), $S\left(f_{k}\right)$, of each time series of $w^{\prime}$ :

$$
S\left(f_{k}\right)=2 \pi^{-2 / 3} \epsilon\left(f_{k}\right)^{2 / 3}\left(\frac{q}{\sqrt{3}}\right)^{2 / 3} f_{k}^{-5 / 3},
$$

where $f_{k}$ is the frequency after a Fourier transformation of the time series (Tennekes and Lumley, 1994). With Equation (1) a value for $\epsilon\left(f_{k}\right)$ on each frequency is obtained. This way of calculating the dissipation rate was termed "single-value method" (Stiansen and Sundby, in press), and showed values in close correspondence with other methods.

A typical PSD plot is shown in Figure 3. It shows that the energy distribution follows closely a $f_{k}^{-5 / 3}$ relationship. Variations over the frequency range for $\epsilon$ are small, so the dissipation rate used from each data file in Figure 2 is simply the mean, $\bar{\epsilon}$. The variation of $\bar{\epsilon}$ during each experiment was small, and all values from experiments $\mathrm{A}-\mathrm{C}$ are in the narrow range $2.8 \times 10^{-4}$ to $6.7 \times 10^{-4} \mathrm{~W} \mathrm{~kg}^{-1}$. The horizontal variation of $\bar{\epsilon}$ cannot be ignored, and decreases to $\sim 0.2$ $\times 10^{-4}$ close to the tank walls, as shown in Figure 2 .

The mean value for experiments $\mathrm{A}-\mathrm{C}$ is $\bar{\epsilon}=3.8 \times 10^{-4}$. If $\bar{\epsilon}$ is increased to $15.0 \times 10^{-4}$, and $q=8.0 \mathrm{~cm} \mathrm{~s}^{-1}$ in Equation (1), the calculated theoretical PSD corresponds closely to the upper $95 \%$ confidence interval of Figure 3. Likewise a value of $\bar{\epsilon}=1.0 \times 10^{-4}$ corresponds to the lower confidence level, hence $\bar{\epsilon}=\left\langle 1.0 \times 10^{-4}, 15.0 \times 10^{-4}\right\rangle$ with $95 \%$ confidence.

The calculated value for $\bar{\epsilon}$ can be compared with the total input of energy by the impellers. The four impellers were measured to use $12.528 \mathrm{~kW}$ on the maximum speed, resulting in a current of $30 \mathrm{~cm} \mathrm{~s}^{-1}$. This is an absolute upper limit for $\bar{\epsilon}$, assuming all this electrical energy was transformed into 


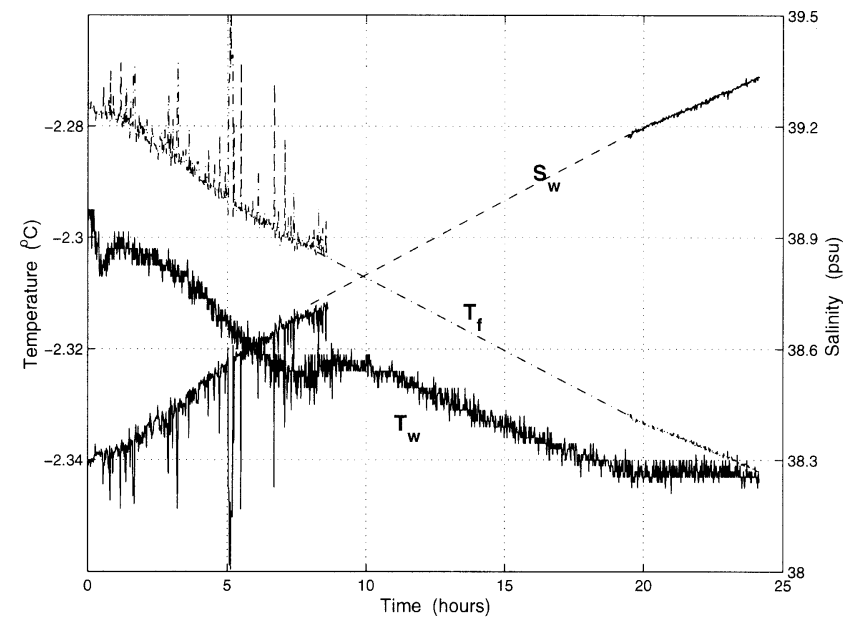

Fig. 4. Water temperature (solid line), salinity (dashed line) and freezing point (dash-dot line) from experiment B. The data gaps (straight line) are caused by frazil crystals blocking the conductivity sensor.

kinetic energy without any loss in the impellers. If the kinetic motion dissipated evenly into heat everywhere in the $93 \mathrm{~m}^{3}$ of tank water, $\bar{\epsilon}=0.13 \mathrm{~W} \mathrm{~kg}^{-1}$. The calculated $\bar{\epsilon}$ is $\sim 0.3 \%$ of this value. Some energy is lost at the impellers, of course, and the local dissipation around the impellers is probably higher than in the test section.

Values for $\epsilon$ in the ocean cover many orders of magnitude, from $10^{-8}$ to $10^{-3} \mathrm{~W} \mathrm{~kg}^{-1}$ (Anis and Moum, 1995). Therefore experiments A-C can be characterized as strongly turbulent, while experiment $\mathrm{D}$ has a value in the middle of the natural range.

\subsection{Temperature and salinity}

The CTD was kept in one fixed position in the test section of the tank, at $0.5 \mathrm{~m}$ depth, $Y=2.3 \mathrm{~m}$ and $X=13.5 \mathrm{~m}$, throughout the experiments (Fig. 1).

The change in salinity for the water is used to calculate the mass of frozen ice, because most salt is expelled during ice formation. However, during the experiments frazil crystals tended to get stuck in the conductivity sensor, and the salinity calculated by the CTD software was too high, as pure sodium chloride $(\mathrm{NaCl})$, and not the usual mix of sea salts, was used in the tank. Equations assuming the water is on the freezing point for $\mathrm{NaCl}$ water were therefore used to give the salinity. The absolute salinity values have an accuracy better than \pm 0.5 psu (Bodnar, 1993).

As soon as the water reached the freezing point, small ice crystals started to appear close to the surface, visible as a faint shimmering at first. The temperature $\left(T_{\mathrm{w}}\right)$, salinity $\left(S_{\mathrm{w}}\right)$ and freezing point $\left(T_{\mathrm{f}}\right)$ from experiment $\mathrm{B}$ are shown in Figure 4. The data are unfiltered, and the small variations in $T_{\mathrm{w}}$ are greater than instrument noise.

Because all experiments were run with similar air temperatures and winds, the evolution of $T_{\mathrm{w}}$ and $S_{\mathrm{w}}$ are similar between experiments, but due to the difficulties with the conductivity, it is hard to determine the exact level of supercooling. For experiment B, $T_{\mathrm{w}}$ decreased by $\sim 0.04^{\circ} \mathrm{C}$ in 24 hours, and $S_{\mathrm{w}}$ increased by about 1 (Fig. 4). For the other experiments see Table 1.

\subsection{Frazil ice}

The initial ice formed in turbulent water bodies is frazil-ice crystals formed in supercooled water. Formation starts

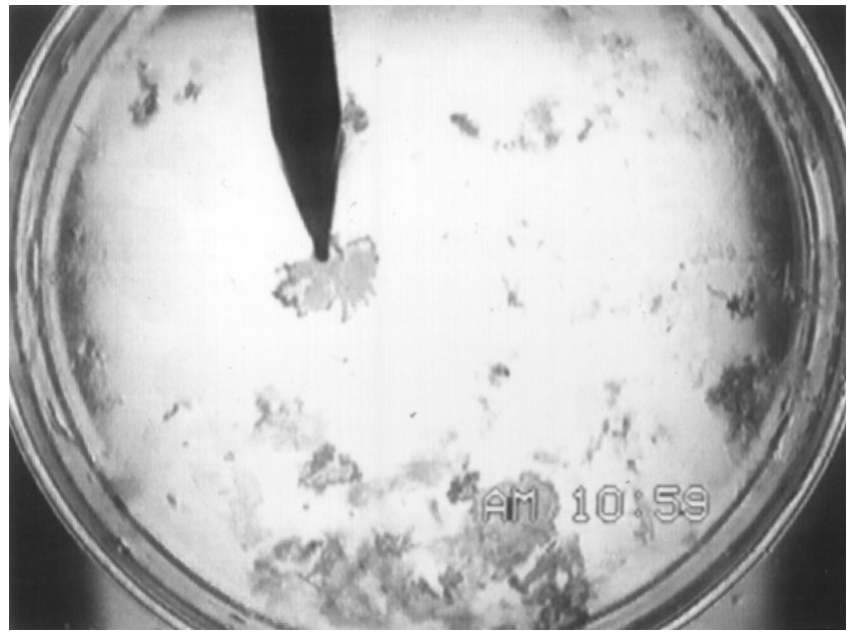

Fig. 5. A typical frazil crystal filmed during experiment D; the diameter of the glass plate is $90 \mathrm{~mm}$.

when the supercooled water is seeded with ice crystals from the air above, and the suspended crystals increase in number and size with time. The heat flux from the crystals to the surrounding water increases with the level of supercooling and with increasing turbulence. When frazil crystals collide, new microscopic crystals are produced, and thus more and more crystals form and grow, as long as heat is removed from the water. Turbulent diffusion transports these crystals downwards into the water column. The distribution of frazil in the water column depends on the balance between downward diffusion and crystal-rise velocity, which is a function of crystal size.

Frazil crystals resembled snowflakes during all experiments. Figure 5 shows a typical frazil crystal. Sometimes the dendritic twigs break off and form a new crystal, and many different crystal habits were observed. No (qualitative) change in the dendritic form was observed. The largest crystals observed were about $2 \mathrm{~cm}$ in diameter, and the thickness was $10-50$ times smaller than this. During the experiments frazil crystals remained separate crystals and did not seem to form frazil flocs.

A frazil-crystal size spectrum was calculated by estimating the number of frazil crystals in five chosen size groups. The size classes and corresponding rise velocities are given in Table 2 (shown later). The "Small" group could not be resolved with the video image, and the concentration here remains unknown. No significant change was found between the different classes over time, so an overall size distribution was calculated (Fig. 6).

The distribution of the frazil sizes at the surface was calculated assuming the crystals are perfect discs, with a mean diameter for each class, and a thickness of $1 / 30$ the diameter. The thickness was not measured directly, only qualitatively estimated as $t_{\mathrm{i}} \sim<1 \mathrm{~mm}$, for the crystals with diameter $\sim 20 \mathrm{~mm}$. Although about $60 \%$ (by number) of the crystals are "Fine", their volume is only $0.006 \%$ of the total, while the 2.5\% "Large" crystals make up about 59\% of the volume. This makes it hard to talk of an average crystal size, but an average diameter of $2 \mathrm{~mm}$ was chosen in the early simplified approach (Smedsrud, 1998).

Frazil-ice concentration at different depths was determined in two ways. The $5 \mathrm{~L}$ water bottle gave an instantaneous measurement where the frazil was "captured" and could be further analyzed, while the absorption meter gave a time evolution of the concentration and therefore a good average value. 


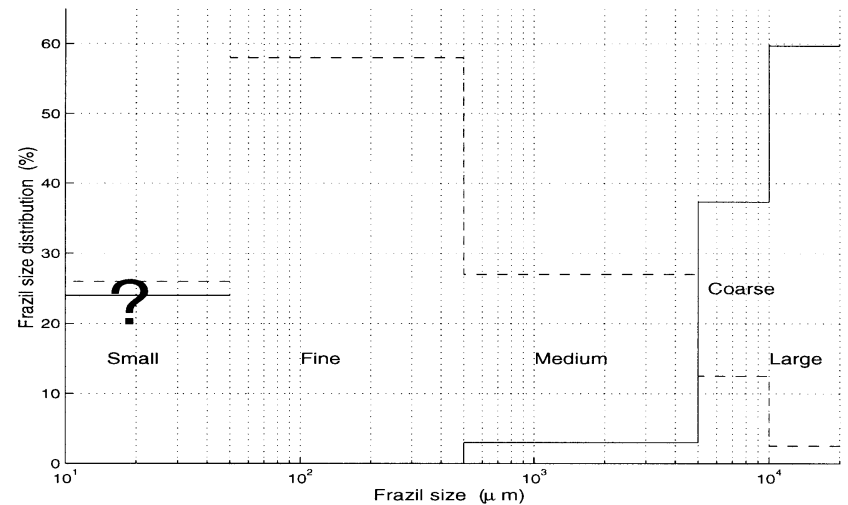

Fig. 6. Average frazil crystal-size distribution in the surface during experiment D. Distribution is plotted as volume distribution (solid line) and number distribution (dashed line).

The "true" mass of frazil ice is defined as the water in a melted bottle sample of slush that has zero salinity, where slush contains an unknown portion of salt water as well as frazil ice. The slush salinity, $S_{\mathrm{s}}$, was in the range 20-28 psu, while salinity of the water, $S_{\mathrm{w}}$, was close to $38 \mathrm{psu}$. This implies a water content of the drained slush of about $60 \%$. The concentration of suspended (pure-water) frazil, $C_{\mathrm{i}}$, was then calculated using the relation;

$$
C_{\mathrm{i}}=\rho_{\mathrm{w}} C_{\mathrm{s}}\left(1-\frac{S_{\mathrm{s}}}{S_{\mathrm{w}}}\right) \text {. }
$$

The slush concentration, $C_{\mathrm{s}}$, is the (melted) mass of the slush divided by the $5 \mathrm{~L}$ bottle volume, and the water density is $\rho_{\mathrm{w}} \sim 1030 \mathrm{~kg} \mathrm{~m}^{-3}$. Results of the water-bottle measurements were in the range $0.1-1.8 \mathrm{~g} \mathrm{~L}^{-1}$ for experiments $\mathrm{A}-\mathrm{C}$, while in experiment $\mathrm{D} C_{\mathrm{i}}$ increased to about $4 \mathrm{~g} \mathrm{~L}^{-1}$, and remained at this level at all depths to the end of the 6 hour experiment (Smedsrud, 1998, Fig. 1).

Figure 7 shows calculated frazil concentration from absorption-meter data that document changes of about $100 \%$ from the mean value over short time-scales. The $a_{\text {rel }}(975)$ values are systematically lower than the $a_{\text {rel }}(900)$ values, due to the presence of frazil ice between the source and the detector of the meter, since ice absorbs less light at $975 \mathrm{~nm}$.
The differences between the absorption-derived mean concentrations and the instantaneous water-bottle values are up to $1 \mathrm{~g} \mathrm{~L}^{-1}$. The absorption-meter data are usually higher than the corresponding water-bottle values for all experiments. Just before the absorption sampling in Figure 13 was done, a water-bottle value showed $0.87 \mathrm{~g} \mathrm{~L}^{-1}$. Although this is only $62 \%$ of the mean, it lies clearly within the observed variation in time.

Figure 8 shows $C_{\mathrm{i}}$ derived from the water-bottle and mean absorption data from experiment C. During the first few hours the difference between the two methods is quite large $\left(\sim 1 \mathrm{~g} \mathrm{~L}^{-1}\right)$, but still within the observed variation in Figure 7 and the other absorption-meter data. Later in the experiment the two methods agree fairly well, so the level of $C_{\mathrm{i}}$ is confirmed to be close to $1 \mathrm{~g} \mathrm{~L}^{-1}$. The average values of $C_{\mathrm{i}}$ from the absorption meter at $0.5 \mathrm{~m}$ depth (Fig. 8) decreased slightly with time despite the growing thickness of the surface slush layer. After 24 hours the slush-layer thickness was approximately $20 \mathrm{~cm}$, although not distributed evenly everywhere in the tank.

Experiments $\mathrm{A}-\mathrm{C}$ had similar levels of $C_{\mathrm{i}}$ from the absorption meter, with average values in the range $0.2-$ $1.5 \mathrm{~g} \mathrm{~L}^{-1}$. After the first few hours, no increase with time below $0.25 \mathrm{~m}$ could be seen. Means of $C_{\mathrm{i}}$ from all depths during experiments are given in Table 1.

\subsection{Sediment}

The sediment added to the tank came from a sand pit near Kiel, Germany. A major fraction of the mass was quartz. Significant volumes of magnesium $(\mathrm{Mg})$, aluminium $(\mathrm{Al})$, potassium $(\mathrm{K})$ and iron $(\mathrm{Fe})$ also existed, indicating a mixture of different minerals.

When sediment was added to the tank, the whole water column changed to a greyish colour. After a few hours with a steady current, a bedload of larger grains was observed on the bottom of the tank in experiments $\mathrm{A}-\mathrm{C}$. In experiment $\mathrm{D}$ no bedload was observed, and the sediment concentration was observed to be homogeneous. In experiments $\mathrm{A}-\mathrm{C}$ the same sediment was used. The grain-size analysis of the bulk sample introduced to the tank (Fig. 9) shows that most of the
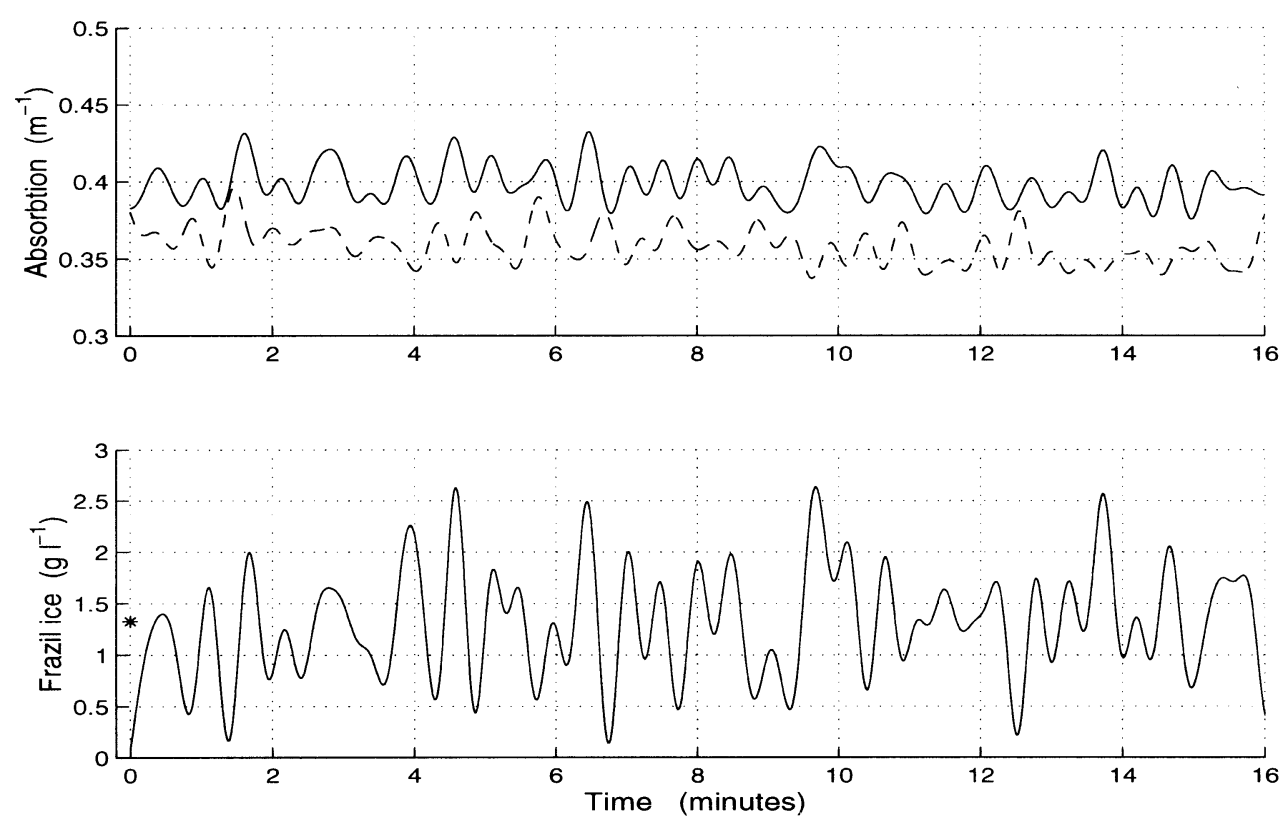

Fig. 7. (a) Low-pass filtered relative absorption coefficients, $a_{\mathrm{rel}}(900)$ (solid line) and $a_{\mathrm{rel}}(975)$ (dashed line). ( $b$ ) Resulting calculated frazil-ice concentration 3 hours into experiment $B$ at $0.25 \mathrm{~m}$ depth. The average value, $\bar{C}_{\mathrm{i}}$, is plotted as *. 


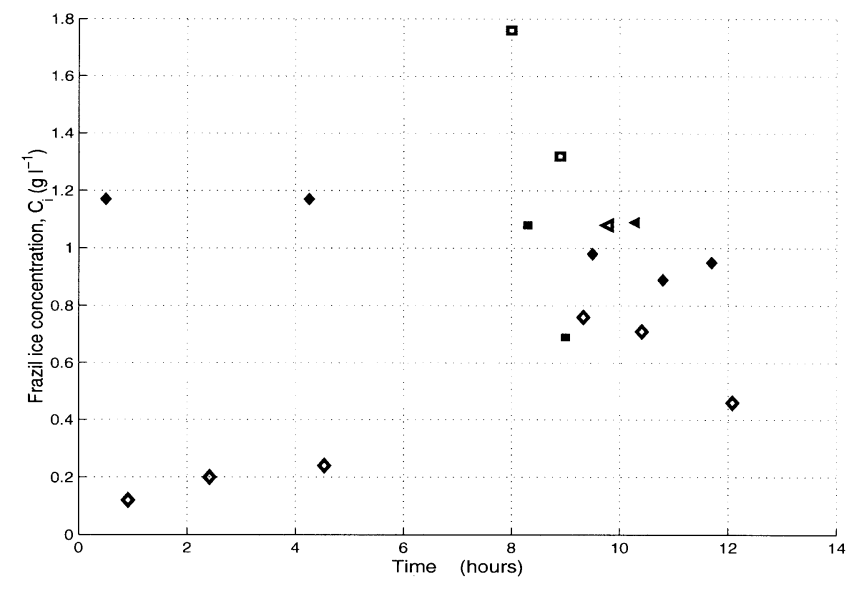

Fig. 8. Measured frazil concentrations, $C_{\mathrm{w}}$ during experiment C. Water-bottle measurements are open symbols; average absorption data are filled symbols. Measurements are from $0.25 \mathrm{~m}(\triangleleft), 0.5 \mathrm{~m}(\diamond)$ and $0.75 \mathrm{~m}$ depth $(\square)$.

sediment $(65 \%)$ is very fine or fine sand $(63-250 \mu \mathrm{m})$. In experiment $\mathrm{D}$, much finer sediment was used. The median size was $2.5 \mu \mathrm{m}$, and all of the grains were silt or clay.

All of the sediment added to the tank water will from now on be termed suspended particulate matter (SPM). The grains that are sampled attached to or within sea ice will be termed ice-rafted sediment (IRS).

Although sediment can have a variety of shapes, a rough generalization is that they are spherical down to the clay fraction. When counting the individual grains from the IRS samples on the SEM screen, it was obvious that this assumption has its limitations. Figure 10 shows a SEM image of a coarse silt particle. The grain-size of the IRS is also plotted in Figure 9. The IRS grain-size is deduced from the two samples in experiment $B$ with the maximum IRS concentration of the slush ice (Fig. 11).

The percentage of mass in each size class is calculated from a mean diameter of the class, assuming all particles are spheres and have the same density. The total mass of the grains in each class depends on the cube of the radius, $r_{\mathrm{s}}^{3}$. So even when the number of grains in the fine-sand fraction is only $\sim 30$ on a given area of the filter, these particles hold $63 \%$ of the mass. In the same area the clay fraction has $\sim 3 \times 10^{5}$ particles, holding only $0.28 \%$ of the mass.

Figure 11 shows the increasing IRS concentrations during experiment $\mathrm{B}$, and the high variation observed. Suspended frazil-ice had high IRS concentrations early in the experiment. After some time, many of the free-floating frazil-ice crystals gathered in the surface as slush, and the maximum sediment concentration in the slush at the end of the experiment was $163 \mathrm{mg} \mathrm{L}^{-1}$.

For the $24 \mathrm{~h}$ experiments $\mathrm{A}-\mathrm{C}$, much of the surface slush consolidated into granular ice during the night when observations could not be performed. In the morning much of the slush ice and the granular ice was discoloured by sediment. The granular ice was sampled and divided into an upper and lower sample, to give an indication of the IRS concentration resulting from this consolidation. This ice contained the greatest IRS concentration of all the experiments, $199 \mathrm{mg} \mathrm{L}^{-1}$ (Fig. 11). This maximum IRS concentration was from the lower sample which represents slush that consolidated fairly close to the time of sampling ( 24 hours). The upper sample of this ice consolidated during the night, so this IRS concentration is moved to 14 hours on the $x$ axis in Figure 11.

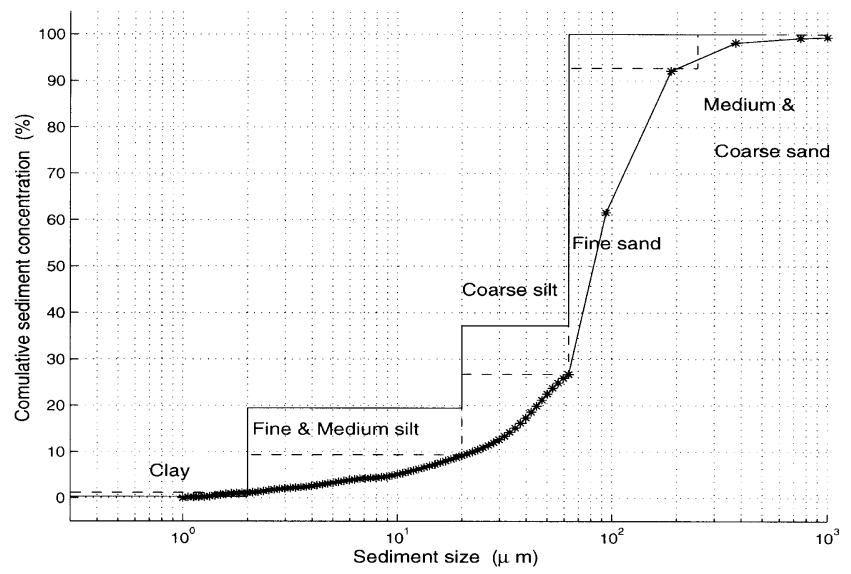

Fig. 9. Cumulative mass frequency for the different size classes of the sediment used in experiments $A-C$. Sizes are from sediment data (-*-), with the five-class approximation shown as --. The counted IRS size distribution is plotted as -

Experiment A showed similar increases in IRS concentration with time, and after about 5 hours the SPM concentration had decreased to less than half. As the turbulence was constant during experiment $\mathrm{A}$, sediment did not settle to the bed in a large degree, and much of the sediment mass had thus been entrained into the ice. In experiment $\mathrm{C}$ the maximum IRS concentration of frazil in suspension was $33.9 \mathrm{mg} \mathrm{L}^{-1}$ at 8 hours at $0.25 \mathrm{~m}$ depth (mean over 2 hours is 22.83, $n=4$ ). Maximum IRS concentrations as well as initial SPM for all experiments are given in Table 1.

\section{DISCUSSION}

Although horizontal differences of the flow cannot be totally ignored, the discussion of the experiment will be one-dimensional. The only feature that showed large horizontal differences was the slush layer. This horizontal heterogeneity of the slush was due to the ice edge at the end of the test section, but this had a minor influence on the flow.

\subsection{Turbulent diffusion}

The calculated values of $\epsilon$ in section 4.1 are in the lower to middle range for earlier small-tank experiments with frazilice formation $\left(0.07-137.5 \times 10^{-3} \mathrm{~W} \mathrm{~kg}^{-1}\right.$ (Daly 1994)). The experiment of Carstens (1966) had a mean velocity of $50 \mathrm{~cm} \mathrm{~s}^{-1}$ in a $20 \mathrm{~cm}$ wide, $30 \mathrm{~cm}$ deep flume, and an $\epsilon$ of the same magnitude, $1.3 \times 10^{-3} \mathrm{~W} \mathrm{~kg}^{-1}$. Eddy viscosities $K$ are commonly used to quantify the turbulent diffusion and are often parameterized by

$$
K=S_{M} l q, \quad\left(\mathrm{~m}^{2} \mathrm{~s}^{-1}\right)
$$

where $S_{M}=0.32$, an empirical constant derived from laboratory experiments for a non-stratified water column (Mellor and Yamada, 1982; Melsom, 1996). The turbulent length scale is $l$, and $q$ is the rms fluctuation velocity of the three directions. Following Mellor and Yamada (1982) again, a calculation of the length scale, $l$, is found from

$$
l=\frac{q^{3}}{16.6 \epsilon},
$$

where $\epsilon$ is the turbulent rate of dissipation. To estimate the 


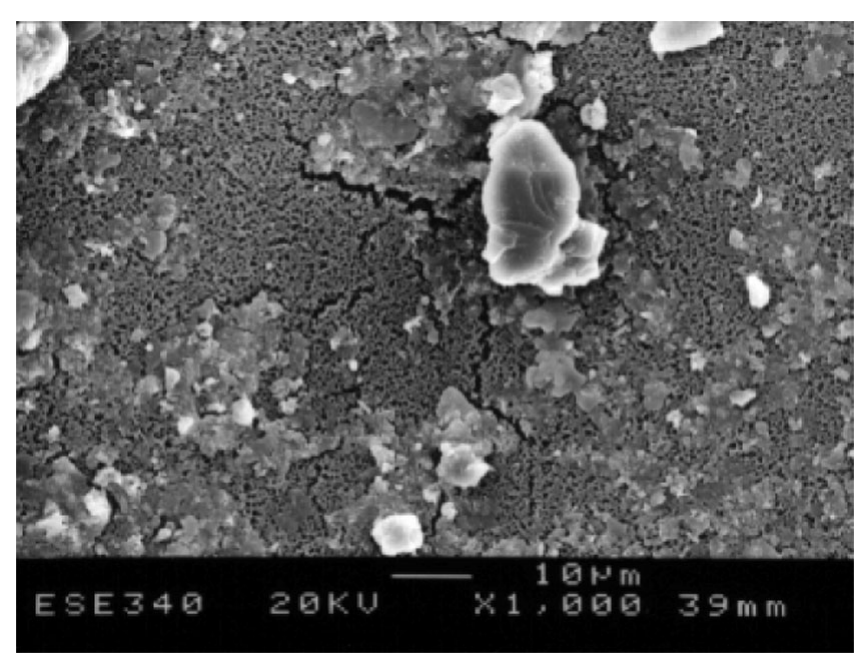

Fig. 10. SEM image of a sediment grain from the coarse-silt size class (diameter $\sim 20 \mu \mathrm{m}$ ), surrounded by smaller grains.

vertical eddy viscosity, $l$ is substituted for from Equation (4), and

$$
K \simeq 0.32 \frac{q^{4}}{16.6 \epsilon} \simeq 3.4 \times 10^{-3},
$$

with the calculated means from experiment $\mathrm{A}$ in Table 1. For experiments B and C, Equation (5) yields similar values for $K$; in contrast, the value from experiment $\mathrm{D}$ is much higher (Table 1).

Towards the walls in the tank, $\epsilon$ decreases to around $0.4 \times 10^{-3}$ with the $30 \mathrm{~cm} \mathrm{~s}^{-1}$ current, while $q$ stays fairly constant (Fig. 2). This indicates that there was a stronger vertical diffusion close to the tank walls than in the middle of the flow in general and $K \sim 18.5 \times 10^{-3}$ at $0.2 \mathrm{~m}$ from the wall.

\subsection{Heat fluxes}

As horizontal differences are omitted in the approach to describe the experiment, the equation for the temperature variation takes the following form:

$$
\frac{\mathrm{D} \bar{T}_{\mathrm{w}}}{\mathrm{d} t}=\frac{\partial \bar{T}_{\mathrm{w}}}{\partial t}+\bar{w} \frac{\partial \bar{T}_{\mathrm{w}}}{\partial z}=\frac{\partial}{\partial z}\left(K \frac{\partial \bar{T}_{\mathrm{w}}}{\partial z}\right)+G_{\mathrm{T}},
$$

where the overbars indicate time averages. The measured decrease in water temperature in Figure 4 corresponds to $\partial \bar{T}_{\mathrm{w}} / \partial t$ in Equation (6). With $\bar{w}=0, \partial \bar{T}_{\mathrm{w}} / \partial t$ is a balance between the turbulent vertical diffusion and the source of heat, $G_{\mathrm{T}}$, from the ice production. There is an insulating bottom boundary, and an upward heat flux, constantly lowering the temperature in the surface. The time series of $T_{\mathrm{w}}$ and $S_{\mathrm{w}}$ are used to calculate two parts of the total upward heat flux $Q_{\mathrm{T}}$.

The flux of heat that results in freezing can be calculated as

$$
\frac{\Delta Q_{\mathrm{f}}}{\Delta t}=\frac{L_{\mathrm{w}} \rho_{\mathrm{w}} \Delta S_{\mathrm{w}} V_{\mathrm{tank}}}{S_{\mathrm{w}} \Delta t}
$$

where $L_{\mathrm{w}}=3.34 \times 10^{5}\left(\mathrm{~J} \mathrm{~kg}^{-1}\right)$ (Yen, 1981), the latent heat of freezing (for fresh water, and fresh frazil crystals). Calculating the average flux from experiment B again, $\Delta S_{\mathrm{w}}=1.05 \mathrm{psu}$, $\Delta t=24$ hours, and $Q_{\mathrm{f}}=10.03 \mathrm{~kW}$, or $Q_{\mathrm{f}}=257.2 \mathrm{~W} \mathrm{~m}^{-2}$ for the open-water area.

A part of the heat flux from the water to the air causes the water to cool down as salinity increases, but this turns out to be as low as $273 \mathrm{~W}$, or $7.0 \mathrm{~W} \mathrm{~m}^{-2}$, for the average heat fluxes over 24 hours. Here the added heat from the molecular

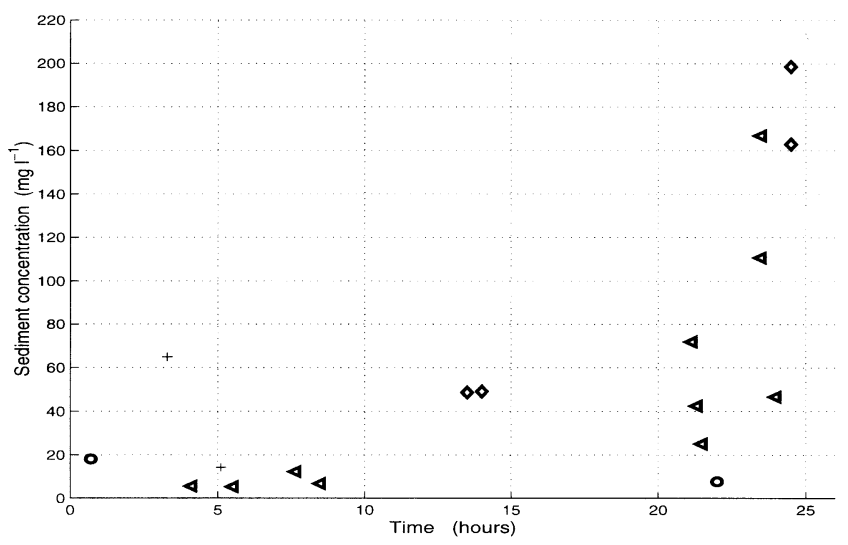

Fig. 11. Sediment concentrations from experiment B. SPM at $0.5 \mathrm{~m}$ depth (०), and IRS from frazil ice in suspension (+), surface slush $(\triangleleft)$ and granularice $(\diamond)$.

dissipation is also taken into account. This part of the heat flux can be ignored as $Q_{\mathrm{f}}$ covers $>98 \%$ of the total flux. Heat fluxes derived from $\Delta S_{\mathrm{w}} / \Delta t$ are given in Table 1 .

The total upward heat fluxes are in the middle of the range for observed heat fluxes for natural Arctic conditions (120-400 $\mathrm{W} \mathrm{m}^{-2}$ ) (Brümmer, 1996), but are in the lower part of the range for smaller laboratory experiments on frazil ice (Daly, 1994).

As short- and longwave radiation as well as evaporation are probably negligible in the cold room, the results can be compared with straightforward bulk sensible-heat-flux parameterizations obtained by dimensional arguments (Gill, 1982):

$$
Q_{\mathrm{S}}=c_{H} \rho_{\mathrm{a}} C_{\mathrm{pa}} U_{\mathrm{a}}\left(T_{\mathrm{w}}-T_{\mathrm{a}}\right),
$$

where $c_{H}$ is a dimensionless coefficient, and a value of $c_{H}=$ $1.1 \times 10^{-3}$ is representative of an open-water situation (Simonsen and Haugan, 1996), $C_{\mathrm{pa}}=1004\left(\mathrm{~J}^{\circ} \mathrm{C}^{-1} \mathrm{~kg}^{-1}\right)$ is the specific heat for air at constant pressure, $\rho_{\mathrm{a}}=1.225 \mathrm{~kg} \mathrm{~m}^{-3}$ is the air density, and $U_{\mathrm{a}}$ is the wind speed. Using values from experiment $\mathrm{B}, U_{\mathrm{a}}=5.0 \mathrm{~m} \mathrm{~s}^{-1}$, and $T_{\mathrm{w}}-T_{\mathrm{a}}=14.87^{\circ} \mathrm{C}$ yields $Q_{\mathrm{S}}=100.6 \mathrm{~W} \mathrm{~m}^{-2}$. In comparison $Q_{\mathrm{T}}$ was $265 \mathrm{~W} \mathrm{~m}^{-2}$.

Using the observed values of $Q_{\mathrm{T}}$ to calculate a mean tank value for the dimensionless coefficient yields $c_{H}=$ $2.73 \times 10^{-3}$. This is comparable to suggested values for $c_{H}$ over leads and thin ice in the Arctic (Simonsen and Haugan, 1996). The increase for $c_{H}$ in the tank, compared to an openwater situation, is probably caused by the unstable conditions for the cold-air flow in the tank, as it is being cooled from the ceiling and therefore will convect down towards the water continuously.

\subsection{Frazil ice}

With the time-scale of several hours in the experiment, the crystals are expected to continue to grow, compared to the small average sizes and total range reported by Daly and Colbeck (1986). As frazil crystals grow in size, their rise velocity also increases, simply because the buoyancy force is proportional to the crystal volume, while the retarding drag force is proportional to the crystal area.

Rise velocities based on Gosink and Osterkamp (1983) are given in Table 2, together with chosen size classes for the crystals. A steady-state situation was reached in $0.2 \mathrm{~s}$ or less for all crystal sizes. For the "Small" crystal class the Reynolds number fell outside the valid range, so the value given is obtained by linear interpolation between zero and the "Fine" class. 
Table 2. Frazil-ice classes (diameter $d_{\mathrm{i}}$ ), and calculated rise velocities based on equations (1-3) in Gosink and Osterkamp (1983)

\begin{tabular}{lccc}
\hline Class & $\begin{array}{c}\text { Range } \\
\mathrm{mm}\end{array}$ & $\begin{array}{c}\text { Median size } \\
\mathrm{mm}\end{array}$ & $\begin{array}{c}\text { Rise velocity } \\
\mathrm{mm} \mathrm{s}^{-1}\end{array}$ \\
\hline Small & $0-0.05$ & 0.025 & 0.005 \\
Fine & $0.05-0.5$ & 0.25 & 0.054 \\
Medium & $0.5-5.0$ & 2.5 & 6.3 \\
Coarse & $5-10$ & 7.5 & 21.2 \\
Large & $10-20$ & 15 & 38.8 \\
\hline
\end{tabular}

According to Martin (1981) and Daly (1984), circular discs up to a few $\mathrm{mm}$ in size are usually observed in the early stages of fresh-water experiments. Such circular discs were not observed at all in these experiments, confirming the results of Hanley (1984). Their absence is probably caused by the fact that salt, as well as heat, has to be removed when a crystal grows in salt water. In addition, the size of the saltwater disc could be significantly smaller than $1 \mathrm{~mm}$. The frazil crystal shape is probably a complicated product of supercooling and turbulence, and no systematic observation of frazil-ice shape and size during growth in salt water has been found in the literature.

Frazil ice is here defined as pure fresh-water crystals. The thin film of salt water between crystals (the interstitial water), or around each crystal, is defined as a part of the water. The production rate of frazil crystal mass per volume $C_{\text {i }}$ can then be calculated exactly by a modified version of Equation (7):

$$
\frac{\Delta C_{\mathrm{i}}}{\Delta t}=\frac{\rho_{\mathrm{w}} \Delta S_{\mathrm{w}}}{S_{\mathrm{w}} \Delta_{\mathrm{t}}}
$$

Using values for experiment $\mathrm{B}$ and $\Delta t=24 \mathrm{~h}$ (Fig. 4), $\Delta C_{\mathrm{i}} / \Delta t=1.17 \mathrm{~g} \mathrm{~L}^{-1} \mathrm{~h}^{-1}$, and the total mass of ice grown during the experiment is $2.62 \times 10^{3} \mathrm{~kg}$. Values for the other experiments are given in Table 1 .

It is a good assumption that all ice freezes as frazil ice since the only other type of ice that was observed to grow was a layer along the tank walls from the surface and $5 \mathrm{~cm}$ downwards. At the end of the experiment, this layer had grown to a thickness of $\sim 3 \mathrm{~cm}$, giving $36 \mathrm{~kg}$ of ice only.

Even with small time increments in Equation (9), $\Delta S_{\mathrm{w}} / \Delta t$ is close to constant for all experiments (see Fig. 4 for experiment $\mathrm{B}$ data). This means that the ice-production rate is close to constant, and that the total volume of ice increases linearly with time.

In contrast, the direct measurements of $C_{\mathrm{i}}$ in suspension during experiment $\mathrm{A}-\mathrm{C}$ show fairly constant levels, i.e. $<2 \mathrm{~g} \mathrm{~L}^{-1}$. This indicates that there is a balance between the downward diffusion and upward rise velocity for a constant portion of the frazil crystals. The increasing volume accumulates in the surface as slush. The $C_{\mathrm{i}}$ in suspension must be the smaller crystals, and as these grow they rise to the surface. But new, small crystals are produced continuously, so there is always a portion of these in suspension.

Experiment $\mathrm{D}$ is different, and has values of $C_{\mathrm{i}}$ up to $4 \mathrm{~g} \mathrm{~L}^{-1}$. With the relatively large $K$, indicating a stronger vertical diffusion, larger crystals were probably kept in suspension than in the other experiments. At the end, slush also gathered on the surface, but more of the ice volume stayed in suspension throughout the experiment.
Table 3. Sediment-size classes and sinking velocities calculated after Neilsen (1992)

\begin{tabular}{lccc}
\hline Class & Range & Median size & Settling velocity \\
& $\mu \mathrm{m}$ & $\mu \mathrm{m}$ & $\mathrm{mm} \mathrm{s}^{-1}$ \\
& & & \\
\hline Clay & $0.3-2$ & 1.15 & -0.0005 \\
Fine and med. silt & $2-20$ & 11.0 & -0.05 \\
Coarse silt & $20-63$ & 41.5 & -0.7 \\
Fine sand & $63-250$ & 156.5 & -10.7 \\
Med. and coarse sand & $250-1000$ & 625 & -171.9 \\
& & & \\
\hline
\end{tabular}

\subsection{Sediment}

With the constant turbulent forcing in the tank, a balance is reached between the upward diffusion and the downward advection of sediment grains, depending on their size and the corresponding settling velocity. The size classes given in Table 3 are the ones used when counting individual grains of the IRS samples. All sizes are given as a diameter of the grains. These five classes approximate the real size distribution as shown in Figure 9.

The sinking velocities (Table 3) are Stokes settling velocities (Neilsen, 1992) using $T_{\mathrm{w}}=-2.0$ and $S_{\mathrm{w}}=35 \mathrm{psu}$, a sediment density of $2650 \mathrm{~kg} \mathrm{~m}^{-3}$ and a depth of $1 \mathrm{~m}$, and they span the rise velocities of the frazil ice (Table 2). So when it is observed that the surface $C_{\mathrm{i}}$ consisted of mostly "Large" crystals, it is also expected that the "Medium and Coarse Sand" grains stay at the bottom.

The real "non-spherical" form of the grains is of importance for the aggregation process, and the likelihood for bonding between a colliding grain and a crystal. A perfect sphere should have less chance to aggregate than a particle with an irregular surface. As the forcing was constant within each experiment, it is expected that the entrainment process operates at a constant rate as well. The frazil crystals in suspension, or in the surface slush, collide with sediment grains, and it is obvious that sediment aggregates to the crystals in some way, and that the concentration of IRS increases with time.

The size distribution of the IRS from Figure 9 shows that no grains larger than $250 \mu \mathrm{m}$ became aggregated to frazil ice. This is consistent with Arctic field observations, where sand fractions of IRS are usually in the range $5-10 \%$, a significantly lower value than for the local bed sediment (Nürnberg and others, 1994), indicating a preferential entrainment of the fine fraction.

The fine-sand fraction $(63-250 \mu \mathrm{m})$ is almost constant between the SPM and the IRS, decreasing from $65 \%$ to $63 \%$. This difference is insignificant given the uncertainties when counting a given size class of particles.

The coarse-silt fraction is constant between the IRS and the SPM, with a difference of only $0.4 \%$. The largest change is for the fine-silt fraction, showing an increase from $8.17 \%$ to $19.41 \%$. This is the compensation for the "lost" sand fraction, and confirms that the sediment entrainment process is selective. Smaller sediment grains aggregate more easily than the larger ones.

The clay fraction is reduced from $1.17 \%$ of the SPM to $0.28 \%$ for the IRS, against expectations. This could be a result of the uncertainties in estimating the mass by counting the particles. For instance, if most of the grains in the size class have a larger diameter than the average used in the 
calculations $(1.15 \mu \mathrm{m})$, a larger percentage by mass would be the result, up to $\sim 2 \%$ when using $r_{\mathrm{s}}=2 \mu \mathrm{m}$. Another explanation could be that the clay is smeared out on the filter. The clay may not look like separate particles, but rather like the "porridge" visible in Figure 10.

The preferential entrainment of smaller particles can be caused by the aggregation process itself. In a $1.9 \mathrm{~m}$ high cylinder, individual frazil crystals tended to become unbalanced and tilted over when loaded by sand grains from the top (Reimnitz and others, 1993). In the tank, the equivalent of this would be that even though the sand grains collide with the frazil crystals, they do not aggregate, but tend to separate after the collision.

In Nature, the selective entrainment of small grains is usually understood to be an indication that suspended sediment is entrained (Nürnberg and others, 1994). Only the fine fraction will usually be suspended outside the strong flow of the delivering river, unless wind and tidal mixing are very strong. In the tank experiment, the equivalent to this would be that the turbulence is not strong enough either to diffuse the larger grains significantly above the tank bottom or to diffuse the frazil crystals down to the bed load.

\subsection{Entrainment and aggregation}

An entrainment factor between the initial or average SPM concentration in the water and the resulting IRS concentration of the formed ice can be defined as

$$
X_{\mathrm{E}}=\frac{\mathrm{IRS}}{\mathrm{SPM}} \text {. }
$$

Here the initial SPM value of each experiment (12.0$\left.18.1 \mathrm{mg} \mathrm{L}^{-1}\right)$ is used. The maximum value of all experiments for the IRS was $198.5 \mathrm{mg} \mathrm{L}^{-1}$. This was from granular ice in experiment B (Fig. 11), making $X_{\mathrm{E}}=11.0$ at 24 hours. For the slush ice, the maximum $X_{\mathrm{E}}$ was 9.2 at 23 hours in experiment $\mathrm{B}$, and for frazil ice in suspension the maximum was $X_{\mathrm{E}}=8.3$ after 4 hours in experiment $\mathrm{A}$. All available measurements of IRS are plotted in Figure 12 as entrainment factors, $X_{\mathrm{E}}$, and maximum values from surface ice (slush and granular) are given in Table 1.

Figure 12 shows that the entrainment process works over long time-scales and that one cannot expect high IRS concentrations if the ice-growth process lasts only a few hours. It is clearly seen that the nature of the process is patchy and that large variations are common, even in a tank with constant forcing.

There is a tendency that $\operatorname{IRS}_{\text {frazil }}>\mathrm{IRS}_{\text {slush }}$ after a few hours in the experiments. This indicates that the suspended frazil scavenges sediment, but, as time passes, these crystals also become a part of the surface slush, bringing the sediment grains along.

A sum of the entrainment process is found in the decreasing SPM concentrations of the tank water, shown at 7 and 22 hours in Figure 12. Since the turbulence was fairly constant it is unlikely that more sediment had been deposited on the tank bottom, and thus the lost SPM was transformed into IRS.

Note that the first surface slush ice that formed had an IRS concentration of zero, and not the SPM concentration of the water, as indicated in Figure 12. It takes about 5-10 hours to reach the initial SPM concentration $\left(X_{\mathrm{E}}=1.0\right)$. After 15 hours all measurements document an enrichment of the ice, i.e. $X_{\mathrm{E}}>1.0$. It has earlier been assumed that frazil or slush will entrain sediment up to the local SPM con-

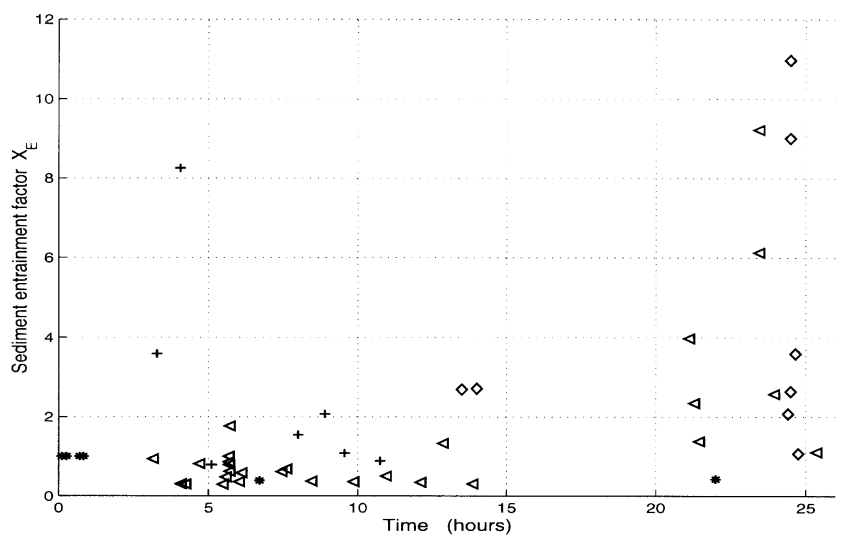

Fig. 12. Sediment entrainment factors, $X_{\mathrm{E}}$ from experiments $A-D$. The initial and end SPM is plotted as *. $X_{\mathrm{E}}$ are from frazil ice in suspension (+), surface slush $(\triangleleft)$ and congealed granularice $(\diamond)$.

centration (Sherwood, 2000), so $X_{\mathrm{E}} \sim 1$ after the entrainment process has taken place. These experiments shows that values as high as $X_{\mathrm{E}} \sim 10$ can be reached within 24 hours, and that $X_{\mathrm{E}} \sim 5$ in about $30 \%$ of the samples. Comparable earlier laboratory experiments report different entrainment factors as outlined below:

Two lead experiments from the same tank were described by Lindemann and Smedsrud (1999). The current was $19 \mathrm{~cm} \mathrm{~s}^{-1}$, and the experiments lasted 16 hours. A layer of $1-5 \mathrm{~cm}$ of granular ice formed in the lead, and $\overline{X_{\mathrm{E}}}=4.0$.

Reimnitz and others (1993) used a vertical tank $(1.9 \mathrm{~m}$ high, $12 \mathrm{~cm}$ wide) filled with sea water, stirred at the bottom for 20-40 $\mathrm{min}$ in their experiments. For 12 experiments $\overline{X_{\mathrm{E}}}=1.48$ with varying SPM concentrations of silt and clay (10.6-5881 $\left.\mathrm{mg} \mathrm{L}^{-1}\right)$, and frazil-ice formation. The range of $X_{\mathrm{E}}$ was $0.7-2.13$. Entrainment showed no particle dependency on the clay and silt fraction.

In a $1.2 \mathrm{~m}$ long tank, with $17 \mathrm{~cm}$ water depth, Kempema and others (1993) found efficient entrainment $\left(X_{\mathrm{E}}\right.$ in the range $2-8)$. This was shortly after frazil formation. They found a decrease of the IRS concentration with time down to $X_{\mathrm{E}}=1.0$ after 2 hours. Experiments were conducted with salt water, and a $70 \mathrm{~cm} \mathrm{~s}^{-1}$ current. Sediment was clay and silt, with SPM concentrations $\sim 100 \mathrm{mg} \mathrm{L}^{-1}$. This was interpreted as frazil being "sticky" only during the time of maximum supercooling, $\sim 0.1^{\circ} \mathrm{C}$ for $5-10 \mathrm{~min}$. The authors claim that frazil loses its ability to bond to sediment when $T_{\mathrm{w}}$ increases to the equilibrium temperature, $\sim 0.02^{\circ} \mathrm{C}$ below $T_{\mathrm{f}}$.

Ackermann and others (1994) report on experiments with high SPM concentrations of fine silt $\left(\sim 10 \mathrm{~g} \mathrm{~L}^{-1}\right)$. Here $\overline{X_{\mathrm{E}}} \sim 0.7$ until maximum supercooling was reached. Experiments were conducted with fresh water, in a $1.15 \mathrm{~m}$ high, $13.8 \mathrm{~cm}$ wide tank, stirred from below. The surprising results were that when sand was used as SPM, much of the frazil crystals sank due to their load, indicating efficient entrainment for this grain-size.

Together these experimental results confirm that frazil ice can aggregate to sediment and can result in surface slush containing sediment.

The cited small-tank experiments likely had much higher turbulence levels than may occur in nature, and also higher 
than during experiments A-D. This could result in an artificially effective entrainment process, creating the $X_{\mathrm{E}} \sim 0.7-8$ on the time-scale of minutes, and with the frazil in a "sticky" mode during the maximum supercooling period.

If the experiments of Ackermann and others (1994) were continued for a longer time, they should then have given higher $X_{\mathrm{E}}$ 's. An explanation for the efficient aggregation between the sand grains and frazil ice could be that the probability of collision between the two is proportional to the cube of the radius of the grains (Smedsrud, 1998). As the frazil loses its "stickiness", these larger grains may disaggregate, as there are no sand grains observed in the IRS in experiments $\mathrm{A}-\mathrm{D}$.

The initial stage of maximum supercooling is mostly due to the laboratory set-up, where cooling is constant and the water is seeded with ice crystals after it has reached supercooling. In nature this probably happens rarely, as there will often be some snow crystals falling into the sea surface when air temperatures are below freezing. During strong wind, sea spray will also freeze and fall back into the water.

Experiments $\mathrm{A}-\mathrm{D}$ did not have these maximum supercooled minutes in the beginning, and $T_{\mathrm{w}}$ is normally $\sim 0.01^{\circ} \mathrm{C}$ below the freezing point. Often this is called the equilibrium temperature. As in nature, this is caused by the snow falling from the ceiling, and also the presence of sea ice around the test section.

The first efficiently entrained sediment might drain out (Kempema and others, 1993) and $X_{\mathrm{E}}$ might come down to unity over a period of time. This may then be comparable to the 5-8 hours in our experiments, with more moderate turbulence forcing. This is consistent with the relatively high $X_{\mathrm{E}}$ 's from frazil ice in suspension at $\sim 4$ hours (Fig. 12).

At longer time-scales, results presented here indicate that entrainment again becomes effective, and that SPM aggregates with frazil ice in the surface (slush), or in suspension. The term "aggregation" is preferred here, and includes any process that leads to bonding between sediment and frazil after a collision. In this way, discussion of weather "scavenging" by frazil crystals, or "filtration processes" by the surface slush as the dominant mechanism (Osterkamp and Gosink, 1984) is avoided. Measurements presented here indicate a continuous flux of frazil from the suspended state to the surface, and there may also be a significant exchange between the two states.

In experiments $\mathrm{A}-\mathrm{D}$, frazil ice in the surface slush appeared to remain as individual crystals, and did not form frazil flocs, confirming the findings of Hanley and Tsang (1984). At some stage this slush congealed into granular ice, but this was usually when the experiments ran unattended during night-time. The idea of the surface slush as a more or less rigid "filter" may therefore only be applied for a maximum period of 12 hours. More likely this should be around 6 hours, as the sampled granular ice was firm and solid. As the lower part of the granular ice had higher levels of IRS, this also indicates that there is no efficient "filtration process" taking place within the solid ice.

Osterkamp and Gosking (1984) noted that a "filtration process" will be most efficient when waves splash over the ice to produce vertical flow, but the experiments presented here show maximum $X_{\mathrm{E}}$ 's in experiments $\mathrm{A}$ and B with no waves. This indicates that such a "filtration process" was not the dominant process. On the contrary, the lower IRS in experiment $\mathrm{C}$ compared to experiment $\mathrm{B}$ may indicate that waves actually make the entrainment process less effective, as experiments $\mathrm{B}$ and $\mathrm{C}$ were quite similar apart from the presence of waves. For the moment, the efficiency of the "filtration process" remains unknown.

Experiment D has very low $\epsilon$, and should thus give lower aggregation according to Smedsrud (1998), because of the lower probability of collisions between sediment and frazil. But it also has high $C_{\mathrm{i}}$ as a consequence of high $K$, and these appear to cancel out, and produce $X_{\mathrm{E}}$ 's around unity, as in the other experiments, around 6 hours.

The highest IRS values are found in experiment B, together with the highest initial SPM, the coldest $T_{\mathrm{a}}$, the largest heat flux and therefore also the highest $\Delta C_{\mathrm{i}} / \Delta t$. This indicates that there is an important link towards ice growth and SPM level in the entrainment and aggregation process. Differences in turbulence are quite small for experiments $\mathrm{A}-\mathrm{C}$, but experiment $\mathrm{B}$ has the lowest $q$ and $K$, indicating that such differences are not important for the entrainment process.

A new version of the numerical model developed in Sherwood (2000) is presently being developed by the author, incorporating the frazil- and sediment-size spectra and the aggregation process presented in Smedsrud (1998). This work will give further insight into the entrainment process.

As these experiments resemble natural settings better than those reported above, it can be expected that an aggregation process is important in explaining how sediment is entrained into Arctic sea ice.

\section{CONGLUSION}

Four experiments are presented that simulate natural freezing processes in shallow Arctic seas. The experiments are comparable to natural conditions for several parameters: sediment size and concentrations, heat fluxes with their associated frazil-ice formation rates, turbulent rms velocities and turbulent dissipation rates.

As the frazil-ice maximum diameter is observed to be around $2 \mathrm{~cm}$, and the sediment is much smaller, the spatial scale of the tank should allow for natural interaction between the two types of particles. The time-scale in the experiment (24 hours) is also comparable to natural timescales for ice formation in Arctic leads or polynyas.

The experimental data show that the mass of sediment entrained into the sea-ice cover formed with a constant level of turbulence increases with time. The ice formed during the experiment had up to 11 times higher concentrations of sediment than the water. Average values were between 2 and 10 in 24 hours. The entrainment depends on: (i) sediment concentration of the water, (ii) low air temperature leading to high heat fluxes and corresponding frazil-ice production, and (iii) strong enough turbulence. Waves do not appear to increase entrainment by frazil ice significantly.

The data presented here should be adequate for verification of numerical models for sediment entrainment into growing ice by aggregation between sediment and frazilice crystals in the surface or in suspension.

\section{ACKNOWLEDGEMENTS}

The author would like to thank the HSVA for technical support and professional execution of the test programme in the ARCTECLAB, and the Commission of the European Communities (TMR-Program "Access to Large-Scale 
Facilities") for financial support and the opportunity to carry out the experiment. H. Eicken and C. Haas (Alfred Wegener Institute) were excellent coordinators of the experiments, and G. Kuhlman and D. Dethleff (Geomar) provided valuable help with the sediment. Thanks also to S. Pegau (Oregon State University) and J. E. Stiansen (Institute of Marine Research, Bergen) for lending the absorption meter and the ADV, E. Kempema for all his suggestions for improvements as a referee, and the scientific editor M. Lange. This work was supported by the Norwegian Research Council, under contract No. 71928/410.

\section{REFERENCES}

Ackermann, N. L., H. T. Shen and B. Sanders. 1994. Experimental studies of sediment enrichment of Arctic ice covers due to wave action and frazil entrainment. F. Geophys. Res., 99 (C4), 7761-7770.

Anis, A. and J. N. Moum. 1995. Surface wave-turbulence interaction: scaling $\varepsilon(z)$ near the sea surface. F. Phys. Oceanogr., 25(9), 2025-2045.

Barnes, P.W., E. Reimnitz and D. Fox. 1982. Ice rafting of fine-grained sediment, a sorting and transport mechanism, Beaufort Sea, Alaska. $\mathcal{F}$. Sediment. Petrol., 52(2), 493-502.

Bodnar, R. J. 1993. Revised equation and table for determining the freezing point depression on $\mathrm{H}_{2} \mathrm{O}-\mathrm{NaCl}$ solutions. Geochim. Cosmochim. Acta, $\mathbf{5 7}$ (3), 683-684.

Brümmer, B. 1996. Boundary-layer modification in wintertime cold-air outbreaks from the Arctic sea. Boundary-Layer Meteorol., 80, 109-125.

Carstens, T. 1966. Experiments with supercooling and ice formation in flowing water. Geofys. Publikasj., 26 (9), 1-18.

Daly, S. F. 1984. Frazil ice dynamics. CRREL Monogr. 84-1.

Daly, S. F. 1994. Frazil ice dynamics. CRREL Spec. Rep. 94-23, 19-24.

Daly, S. F. and S. C. Colbeck. 1986. Frazil ice measurements in CRREL's flume facility. In IAHR86, 8th International Symposium on Ice, 18-22 August 1986, Iowa City, Iowa. Proceedings. Iowa City, IA, International Association for Hydraulic Research, 427-438.

Eicken, H. and 20 others. 1999. Ice tank studies of physical and biological seaice processes. In Shen, H. T., ed. Ice in surface waters. Vol. 1. Rotterdam, A. A. Balkema, 363-370.

Eicken, H., J. Kolatschek, J. Freitag, F. Lindemann, H. Kassens and I. Dmitrenko. 2000. A key source area and constraints on entrainment for basin-scale sediment transport by Arctic sea ice. Geophys. Res. Lett., 27(13), 1919-1922.

Gill, A. E. 1982. Atmosphere-ocean dynamics. San Diego, Academic Press. (International Geophysics Series 30.)

Gosink, J. P. and T. E. Osterkamp. 1983. Measurements and analyses of velocity profiles and frazil ice-crystal rise velocities during periods of frazil-ice formation in rivers. Ann. Glaciol., 4, 79-84.

Haas, C. and 10 others. 1999. Multidisciplinary ice tank study shedding new light on sea ice growth processes. Eos, 80 (43), 507, 509, 513.

Hanley, T. O'D., SJ and G. Tsang. 1984. Formation and properties of frazil in saline water. Cold Reg. Sci. Technol., 8 (3), 209-221.

Kempema, E.W., E. Reimnitz, J. R. Clayton, Jr and J. R. Payne. 1993. Interactions of frazil and anchor ice with sedimentary particles in a flume. Cold Reg. Sci. Technol., 21 (2), 137-149.

Landa, E. R., E. Reimnitz, D. M. Beals, J. M. Pochkowski, W. G. Winn and I. Rigor. 1998. Transport of ${ }^{137} \mathrm{Cs}$ and ${ }^{239,240} \mathrm{Pu}$ with ice-rafted debris in the Arctic Ocean. Arctic, 51 (1), 27-39.

Lindemann, F. and L. H. Smedsrud. 1999. Sediment entrainment into sea ice in Arctic leads: an experimental approach. In Shen, H. T., ed. Ice in surface waters. Vol. 1. Rotterdam, A. A. Balkema, 387-390.

Martin, S. 1981. Frazil ice in rivers and oceans. Annu. Rev. Fluid Mech. 13,379-397.

Mellor, G. L. and T. Yamada. 1982. Development of a turbulent closure model for geophysical fluid problems. Reviews of Geophysics and Space Physics, 20(4), 851-875.

Melsom, A. 1996. A review of the theory of turbulence closure due to Mellor and Yamada, and its implementation in the Princeton ocean model. Oslo, Norwegian Meteorological Institute. (Research Report 38.)

Neilsen, P. 1992. Coastal bottom boundary layers and sediment transport. Singapore, World Scientific.

Nürnberg, D. and 7 others. 1994. Sediment in Arctic sea ice: implications for entrainment, transport and release. Mar. Geol., 119(3/4), 185-214.

Osterkamp, T. E. and J. P. Gosink. 1984. Observations and analysis of sediment-laden sea ice. In Barnes, P.W., D. M. Scholl and E. Reimnitz, eds. The Alaskan Beaufort Sea: ecosystems and environments. Orlando, FL, Academic Press, 73-94.

Pegau, W. S., C. A. Paulson and R. Z. Zaneveld. 1996. Optical measurements of frazil concentration. Cold Reg. Sci. Technol., 24(4), 341-353.

Reimnitz, E., L. Marincovich, Jr, M. McCormick and W. M. Briggs. 1992. Suspension freezing of bottom sediment and biota in the Northwest Passage and implications for Arctic Ocean sedimentation. Can. 7. Earth Sci., 29(4), 693-703.

Reimnitz, E., J. R. Clayton, Jr, E. W. Kempema, J. R. Payne and W. S. Weber. 1993. Interaction of rising frazil with suspended particles: tank experiments with applications to nature. Cold Reg. Sci. Technol., 21(2), 117-135.

Sherwood, C. R. 2000. Numerical model of frazil-ice and suspendedsediment concentrations, and formation of sediment-laden ice in the Kara Sea. 7. Geophys. Res., 105(C6), 14,061-14,080.

Simonsen, K. and P. M. Haugan. 1996. Heat budgets for the Arctic Mediterranean and sea surface heat flux parameterizations for the Nordic Seas. 7. Geophys. Res., 101 (C3), 6553-6576.

Smedsrud, L. H. 1998. Estimating aggregation between suspended sediments and frazil ice. Geophys. Res. Lett., 25 (20), 3875-3878.

Smedsrud, L. H. 2000. Frazil ice formation and incorporation of sediments into sea ice in the Kara Sea. (Ph.D. thesis, University of Bergen. Geophysical Institute.)

Stiansen, J. and S. Sundby. In press. Improved methods for generating and estimating turbulence in tanks suitable for fish larvae experiments. Scientia Marina.

Tennekes, H. and J. L. Lumley. 1994. A first course in turbulence. New edition. Cambridge, MA, MIT Press.

Yen, Y.-C. 1981. Review of thermal properties of snow, ice and sea ice. CRREL Rep. 81-10. 